\title{
Effect of negative energy balance on plasma metabolites, minerals, hormones, cytokines and ovarian follicular growth rate in Holstein dairy cows
}

\author{
Yuxi Song*, Zhijie Wang*, Chang Zhao, Yunlong Bai, Cheng Xia ${ }^{\bowtie}$, Chuang Xu \\ Heilongjiang Provincial Key Laboratory of Prevention and Control of Bovine Diseases, \\ College of Animal Science and Veterinary Medicine, Heilongjiang Bayi Agricultural University, \\ Sartu District, Daqing 163319, PR China \\ xcwlxyf@sohu.com
}

Received: December 30, 2020 Accepted: June 15, 2021

\begin{abstract}
Introduction: The aim of this study was to evaluate the effect of negative energy balance (NEB) on the final growth of the dominant ovarian follicle in Holstein cows. Material and Methods: Cows at 14 to $21 \mathrm{~d}$ postpartum from an intensive dairy farm were randomly selected and allocated into a positive energy balance group (PEB, with $\beta$-hydroxybutyric acid (BHBA) level $<1.2 \mathrm{mmol} / \mathrm{L}, \mathrm{n}=15$ ) and an NEB group (BHBA $>1.2 \mathrm{mmol} / \mathrm{L}, \mathrm{n}=15$ ). Plasma samples were collected at 21,50 and $55 \mathrm{~d}$ postpartum to assess the concentrations of energy metabolites, minerals, hormones and cytokines. Ovaries were examined by transrectal ultrasound on days 50 and 55 (120 hours later) to evaluate the diameter of the largest follicle. Results: Compared with PEB cows, there were a more severe body condition loss and a lower milk yield in NEB cows $(\mathrm{P}<0.05)$ and these had greater concentrations of plasma BHBA, non-esterified fatty acids, triglycerides, urea nitrogen, growth hormone, interleukin 6 , and fibroblast growth factor 21 and lesser concentrations of plasma glucose, total cholesterol, insulin, insulin-like growth factor 1, insulin-like growth factor binding protein 3, leptin, brain-derived neurotrophic factor and angiopoietin-like protein 8 on $\mathrm{d} 21$ ( $\mathrm{P}<0.05$ ), while plasma minerals were not affected by energy status $(\mathrm{P}>0.05)$. These changes persisted until the end of the study period (50-55 days postpartum) resulting in a lower follicular growth rate for cows in the NEB than the PEB group. Conclusion: These observations indicate that follicular growth rate is associated with measurable changes in energy metabolite, hormone and cytokine concentrations caused by early postpartum NEB.
\end{abstract}

Keywords: dairy cow, negative energy balance, plasma, follicle.

\section{Introduction}

In early lactation, almost all dairy cattle undergo a period of negative energy balance (NEB), metabolic stress, and a degree of body condition loss $(\triangle \mathrm{BCS})$ due to mobilisation of body reserves in response to increased energy requirements for lactogenesis $(3,27)$. Negative energy balance can potentially lead to development of ketosis and elevated levels of ketone bodies in body fluids, such as acetone, acetoacetate, and $\beta$-hydroxybutyric acid (BHBA) $(6,11)$. Therefore, in previous studies, NEB was defined as non-esterified fatty acids (NEFA) $>0.7 \mathrm{mEq} / \mathrm{L}$ or $\mathrm{BHBA} \geq 1.2 \mathrm{mmol} / \mathrm{L} \mathrm{(2).}$

Negative energy balance is considered to be an important reason for poor reproductive performance. After calving, cows suffering from NEB are often mineral deficient, as energy demands increase 2.5 times while requirements for minerals such as calcium and magnesium can double (19). Altered metabolite and hormone concentrations may influence follicular growth (36). Although many factors affect postpartum anoestrus, nutrition and lactation are the major factors influencing the resumption of postpartum ovarian cycles, as they affect hypothalamic, pituitary and ovarian activity and thus inhibit follicular development (20). In addition, the main cytokines secreted by mammalian adipose tissue including leptin (LEP), adiponectin (ADPN), and tumour necrosis factor- $\alpha$ (TNF- $\alpha$ ) are mainly implicated in energy balance, regulation of appetite and metabolism, and maintenance of homeostasis, but their influence on follicular growth is unclear (10).

Cows are polyoestrous animals and display oestrous behaviour approximately every 21 days (d). The normal 
duration of an oestrous cycle in cows is 18-24 d (9). The development of dominant follicles in dairy cows is a key part of the oestrous cycle and their growth rate affects oestrous cycle length in cows. Previous studies have shown that using the Presynch regimen may help to achieve satisfactory conception and pregnancy rates at 51-65 days in milk (DIM) in cows (5). Cows in which a Presynch-Ovsynch protocol was implemented had a voluntary waiting period of 50 DIM (30). The hypothesis that will be tested is that ovarian follicular growth rate is associated with measurable changes in energy metabolite, hormone and cytokine concentrations caused by early postpartum NEB. Therefore, we aimed to study the effect of early-lactation NEB (i.e., plasma BHBA concentration $\geq 1.2 \mathrm{mmol} / \mathrm{L}$ during the first three weeks in milk) on dominant follicle growth rate in the 50-55 d postpartum period.

\section{Material and Methods}

Animals. This prospective observational experiment was conducted on a commercial farm in Heilongjiang Province, China, from September 2019 to January 2020. Thirty clinically healthy Holstein cows at 14 to $21 \mathrm{~d}$ postpartum were randomly chosen and assigned appropriately to a positive energy balance group (PEB, BHBA $<1.2 \mathrm{mmol} / \mathrm{L}, \mathrm{n}=15$ ) or a negative energy balance group (NEB, BHBA > $1.2 \mathrm{mmol} / \mathrm{L}, \mathrm{n}=15$ ). Subsequently, the cows were followed until $55 \mathrm{~d}$ postpartum and received no treatment before the end of the study period except oestrous synchronisation. All cows were 2-4 years old, with parity of $1-3$, and suffering no other clinical disorders. The subject animals were maintained in free-stall housing with continuous access to fresh water and were milked three times per day. Total mixed rations during early lactation were formulated in accordance with the 2001 US National Research Council standards.

All cows were synchronised using a Double-Ovsynch protocol for the first timed artificial insemination with a progesterone implant during the synchronisation (30). Briefly, the protocol was initiated with an intramuscular injection of gonadotropin-releasing hormone (GnRH) (100 $\mu \mathrm{g}$; Pfizer Animal Health, New York, NY, USA) at $40 \pm 3 \mathrm{~d}$ postpartum, followed $7 \mathrm{~d}$ later by an injection of prostaglandin F2 alpha (PGF2 $\alpha$ ) (25 mg; Pfizer Animal Health) and a further 3 d later by another $\mathrm{GnRH}$ $(100 \mu \mathrm{g})$ injection. At $7 \mathrm{~d}$ after the second GnRH administration, the ovulation synchronisation protocol was initiated by administering another $100 \mu \mathrm{g}$ of GnRH and inserting an intravaginal progesterone controlled internal drug release device (Eazi-Breed CIDR; InterAg, Hamilton, New Zealand) for $7 \mathrm{~d}$. Cows received an injection of $25 \mathrm{mg}$ PGF2 $\alpha$ at the time of CIDR device removal. A final GnRH dose $(100 \mu \mathrm{g})$ was given $56 \mathrm{~h}$ after the PGF2 $\alpha$ injection and insemination was simultaneous with the last $\mathrm{GnRH}$ injection and 16 to $20 \mathrm{~h}$ later (at an average of $67 \mathrm{~d}$ postpartum).
Sample collection. At 21, 50 and 55 d postpartum, before milking and fasting in the morning, $10 \mathrm{~mL}$ of blood was collected from the jugular vein into an anticoagulant tube and mixed evenly with three drops of heparin sodium. Anticoagulated blood was centrifuged at 1,500 $\times \mathrm{g}$ for $5 \mathrm{~min}$ and the supernatant was placed into a $1.5 \mathrm{~mL}$ Eppendorf tube. Then, the supernatant was centrifuged at $12,000 \times \mathrm{g}$ for $5 \mathrm{~min}$ and $500 \mu \mathrm{L}$ of plasma was transferred into a $1.5 \mathrm{~mL}$ Eppendorf tube and stored at $-80^{\circ} \mathrm{C}$ for biochemical analysis, radioimmunoassay and ELISA.

Plasma analysis. $\beta$-hydroxybutyric acid, NEFA, glucose (GLU), triglycerides (TG), total cholesterol (TC), urea nitrogen (UN), calcium, phosphorus and magnesium in plasma were analysed using commercial biochemical assay kits (Mindray Biomedical Electronics Co. Ltd, Shenzhen, China). All metabolite concentrations were quantified using a BS-830S fully automatic biochemistry analyser (Mindray Biomedical Electronics). All measurements were executed according to the manufacturers' instructions.

Estradiol (E2), progesterone (P4), insulin (INS) and growth hormone $(\mathrm{GH})$ concentrations were measured using four commercial kits with the same lot number (Xinfan Biotechnology Co. Ltd, Shanghai, China) and the kit manufacturer's validated radioimmunoassay procedures. Assay sensitivities were $2 \mathrm{pg} / \mathrm{mL}$ (E2), $0.2 \mathrm{ng} / \mathrm{mL}$ (P4), $2 \mu \mathrm{IU} / \mathrm{mL}$ (INS) and $10 \mathrm{ng} / \mathrm{mL}(\mathrm{GH})$. The intra-assay coefficients of variation (CVs) were less than $10 \%$ and the inter-assay coefficients of variation (CV) less than $15 \%$.

The quantities of insulin-like growth factor 1 (IGF-1), insulin-like growth factor binding protein-3 (IGFBP3), TNF- $\alpha$, LEP, ADPN, fibroblast growth factor 21 (FGF21), angiopoietin-like protein 8 (ANGPTL8), interleukin-6 (IL-6) and brain-derived neurotrophic factor (BDNF) were detected using matching lot number ELISA kits purchased from Xinfan Biotechnology Co., Ltd. and used in accordance with the manufacturer's instructions.

Data collection. Age, parity and milk yield (MY) data were collected from the Afitag pedometers (Afimilk 0418A09QPDX, Kibbutz Afikim, Israel) of the cattle farm. Body condition was scored weekly by two trained farm veterinarians using the established five-point method (4).

Ultrasound examinations. All cows were submitted to transrectal examination of the ovaries using a DP-2200 VET ultrasonograph (Mindray Biomedical Electronics) on d 50 and d 55 (120 hours later) to evaluate the diameter of the largest follicle and to calculate the follicular growth rate between these two days. The final daily follicular growth rate was calculated as the difference between the largest follicle diameters on d 50 and d 55 divided by five.

Statistical analysis. The sampling unit was a cow and was treated as a random effect in all models. All analyses were performed using IBM SPSS Statistics for Windows v. 19.0 software (IBM Corp., Armonk, NY, 
USA). Clinical data (age, parity, BCS, MY) and follicle data (diameter and growth rate) of cows were analysed for significant differences between the PEB and NEB groups using the independent samples $t$-test. All plasma indicators assessed on $\mathrm{d} 21, \mathrm{~d} 50$, and $\mathrm{d} 55$ were analysed using a mixed model procedure to account for correlated repeated measures. The model consisted of the fixed effects of energy status (PEB vs. NEB), number of DIM, and relationship between DIM and energy status. Probability values $<0.05$ and $<0.01$ were considered significant and very significant, respectively.

\section{Results}

Background information of the tested cows. The age, parity, BCS and MY of cows are shown in Table 1. There were a significant increase in $\triangle \mathrm{BCS}(\mathrm{P}<0.05)$ and decrease in MY $(\mathrm{P}<0.01)$ in the NEB group compared with those of the PEB group.

Table 1. Clinical data from the two groups of cows

\begin{tabular}{lccc}
\hline Parameter & PEB $(\mathrm{n}=15)$ & NEB $(\mathrm{n}=15)$ & P value \\
\hline Age & $3.49 \pm 0.35$ & $3.45 \pm 0.38$ & 0.942 \\
Parity & $2.47 \pm 0.32$ & $2.20 \pm 0.33$ & 0.565 \\
$14-21 \mathrm{~d} \mathrm{BCS}$ & $3.18 \pm 0.09$ & $3.38 \pm 0.07$ & 0.094 \\
$50-55 \mathrm{~d} \mathrm{BCS}$ & $2.97 \pm 0.09$ & $2.88 \pm 0.09$ & 0.522 \\
$\Delta B C S$ & $0.22 \pm 0.01$ & $0.50 \pm 0.08$ & 0.025 \\
MY $(\mathrm{kg} / \mathrm{d})$ & $42.32 \pm 1.36$ & $36.76 \pm 1.46$ & 0.010 \\
\hline
\end{tabular}

PEB - positive energy balance; NEB - negative energy balance; BCS - body condition score; $\triangle \mathrm{BCS}$ - body condition score loss; MY average daily milk production in the first 55 days in milk

Table 2. Least squares means \pm SEM of the largest follicle diameter on days 50 and 55 and the growth rate between days 50 and 55 in Holstein cows

\begin{tabular}{lccc}
\hline Parameter & PEB $(\mathrm{n}=15)$ & NEB $(\mathrm{n}=15)$ & P value \\
\hline LF diameter on d 50 (mm) & $6.53 \pm 0.97$ & $7.07 \pm 0.90$ & 0.690 \\
LF diameter on d 55 (mm) & $12.27 \pm 0.66$ & $10.53 \pm 0.93$ & 0.138 \\
Growth rate of the LF (mm/d) & $1.19 \pm 0.13$ & $0.68 \pm 0.11$ & 0.007
\end{tabular}

LF - largest follicle; PEB - positive energy balance; NEB - negative energy balance

Follicular growth status of the tested cows. No differences were observed for the diameter of the largest follicle at $50 \mathrm{~d}(\mathrm{P}>0.05)$ or $55 \mathrm{~d}(\mathrm{P}>0.05)$ between the PEB and NEB groups, whereas the growth rate of the dominant follicle from $\mathrm{d} 50 \mathrm{~d}$ to $\mathrm{d} 55 \mathrm{~d}$ was lower for the NEB group $(\mathrm{P}<0.01)$ (Table 2$)$.

The effect of NEB on plasma energy metabolites. The changes in energy metabolic indices are shown in Fig. 1. Plasma concentrations of BHBA, NEFA, GLU, TC and UN were significantly affected by energy balance and DIM $(\mathrm{P}<0.05)$. Interactions were also detected for plasma BHBA and GLU concentrations between treatment and DIM $(\mathrm{P}<0.01)$. At $21 \mathrm{~d}$ postpartum, the NEB group was found to have significantly higher plasma concentrations of BHBA $(\mathrm{P}<0.01)$, NEFA $(\mathrm{P}<0.01)$, TG $(\mathrm{P}<0.05)$ and $\mathrm{UN}(\mathrm{P}<0.01)$ and lower plasma concentrations of GLU $(\mathrm{P}<0.01)$ and TC $(\mathrm{P}<0.01)$ compared to the PEB group. Noteworthily, except for TG and UN, this difference in energy metabolites would continue until $50 \mathrm{~d}$ to $55 \mathrm{~d}$ postpartum.

The effect of NEB on plasma minerals. The changes in mineral indices are shown in Fig. 2. Plasma concentrations of $\mathrm{Ca}, \mathrm{P}$ and $\mathrm{Mg}$ were not significantly affected by energy balance $(\mathrm{P}>0.05)$, but were by number of DIM $(\mathrm{P}<0.05)$. No interactions were detected for plasma $\mathrm{Ca}, \mathrm{P}$ and $\mathrm{Mg}$ concentrations between treatment and DIM $(\mathrm{P}>0.05)$. No differences were found between the $\mathrm{PEB}$ and NEB groups regarding $\mathrm{Ca}, \mathrm{P}, \mathrm{Mg}$ concentrations at 21,50 , or 55 d postpartum $(\mathrm{P}>0.05)$.

The effect of NEB on plasma hormones. The changes in hormone indices are shown in Fig. 3. Energy balance had a significant effect on plasma INS, GH, IGF-1, IGFBP-3 and LEP concentrations $(\mathrm{P}<0.05)$, but had no significant effect on plasma E2 and P4 concentrations $(\mathrm{P}>0.05)$. The number of DIM had a significant effect on plasma E2, P4 and INS concentrations $(\mathrm{P}<0.05)$, but had none on plasma $\mathrm{GH}$, IGF-1, IGFBP-3 or LEP concentrations $(\mathrm{P}>0.05)$. No interactions were detected for plasma hormone concentrations between treatment and DIM ( $\mathrm{P}>0.05)$. At $21 \mathrm{~d}$ postpartum, assays of the NEB group plasma revealed significantly more concentrated GH $(\mathrm{P}<0.01)$ and less concentrated INS ( $\mathrm{P}<0.01)$, IGF-1 $(\mathrm{P}<0.05)$, IGFBP-3 $(\mathrm{P}<0.05)$ and LEP $(\mathrm{P}<0.05)$ compared to the PEB group plasma. Since E2 and P4 levels fluctuate over the oestrous cycle of cows, they exhibited relatively low levels in plasma in the NEB group. Except for $\mathrm{GH}$, this difference in other hormones would continue until 50 to $55 \mathrm{~d}$ postpartum as it also did when energy metabolites were investigated in NEB.

The effect of NEB on plasma cytokines. The changes in cytokine indices are shown in Fig. 4. Negative energy balance had a significant effect on plasma IL-6, ANGPTL8, FGF21 and BDNF concentrations $(\mathrm{P}<0.05)$, but none on those of plasma TNF- $\alpha$ or ADPN $(\mathrm{P}>0.05)$. The number of DIM had no significant effect on the plasma concentrations of IL-6, TNF- $\alpha$, ANGPTL8, FGF21, BDNF or ADPN (P > 0.05). No interactions were detected for plasma cytokine concentrations between treatment and DIM $(\mathrm{P}>0.05)$. At $21 \mathrm{~d}$ postpartum, the NEB group IL-6 and FGF21 plasma concentrations were significantly higher ( $\mathrm{P}<0.05$ in both cases) and those of ANGPTL8 and BDNF significantly lower ( $P<0.05$ in both cases) compared to the PEB group equivalents. As observed analogously for energy metabolites and hormones except for IL-6, this difference in other cytokines would continue until $50 \mathrm{~d}$ to $55 \mathrm{~d}$ postpartum. 


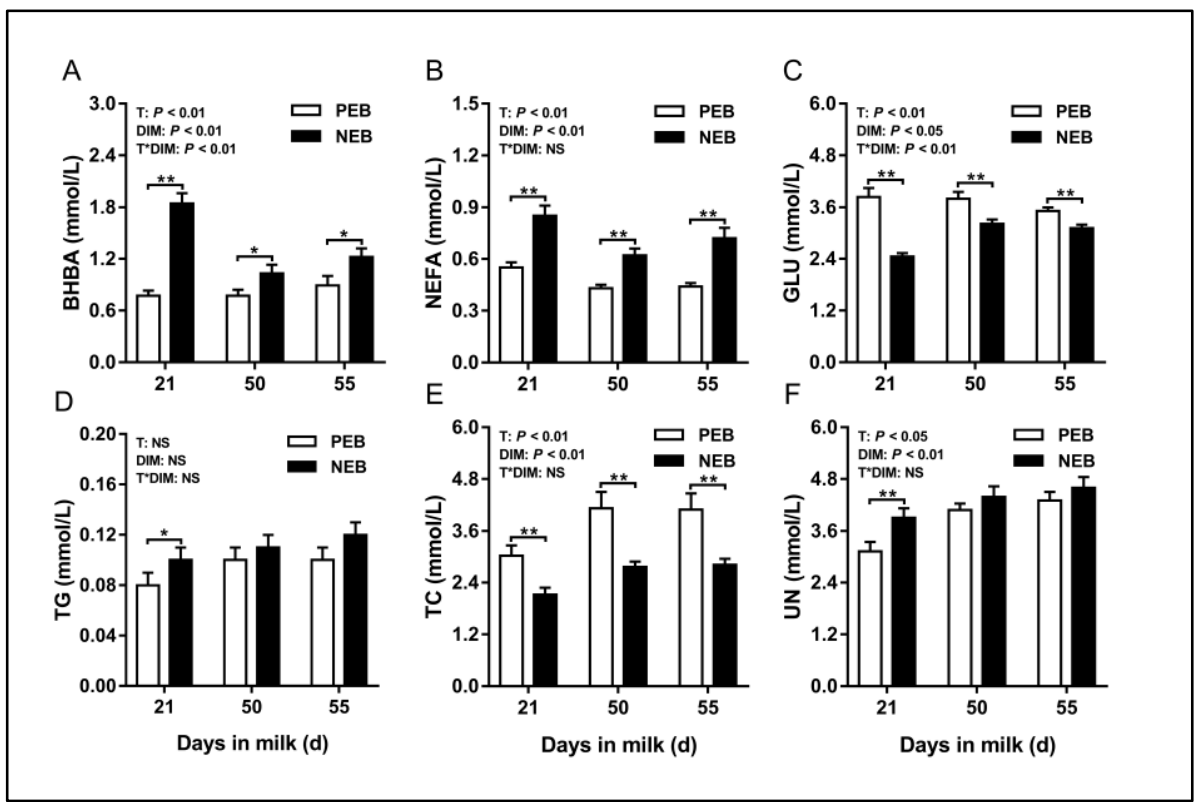

Fig. 1. Least squares mean $( \pm$ SEM) concentrations of plasma $\beta$-hydroxybutyric acid, non-esterified fatty acids, glucose, triglycerides, total cholesterol, and urea nitrogen at 21, 50, and $55 \mathrm{~d}$ after calving for positive energy balance $(\mathrm{PEB})(\mathrm{n}=15)$ and negative energy balance $(\mathrm{NEB})(\mathrm{n}=15)$ dairy cows

$\mathrm{T}$ - treatment group; DIM - days in milk; T $\times$ DIM - interaction between treatment group and days in milk

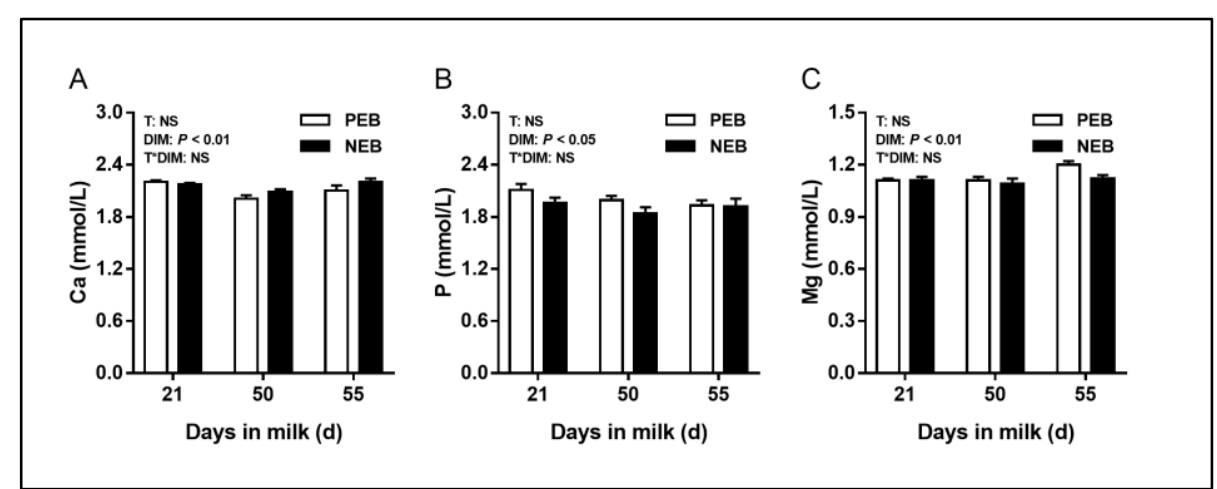

Fig. 2. Least squares mean $( \pm \mathrm{SEM})$ concentrations of plasma $\mathrm{Ca}, \mathrm{P}$, and $\mathrm{Mg}$ at 21,50 , and $55 \mathrm{~d}$ after calving for positive energy balance (PEB) $(n=15)$ and negative energy balance $(\mathrm{NEB})(\mathrm{n}=15)$ dairy cows

$\mathrm{T}$ - treatment group; DIM - days in milk; $\mathrm{T} \times \mathrm{DIM}$ - interaction between treatment group and days in milk

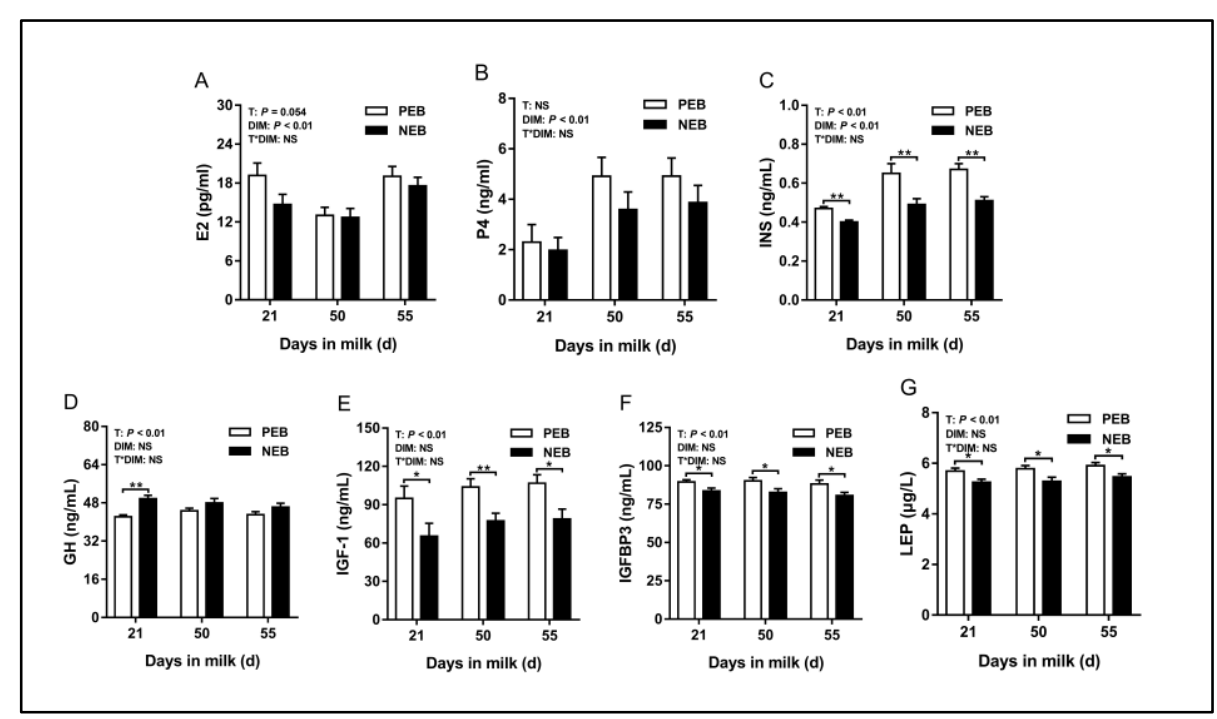

Fig. 3. Least squares mean ( \pm SEM) concentrations of plasma E2, P4, INS, GH, IGF-1, IGFBP3, and LEP at 21,50 , and $55 \mathrm{~d}$ after calving for positive energy balance $(\mathrm{PEB})(\mathrm{n}=15)$ and negative energy balance (NEB) $(n=15)$ dairy cows

$\mathrm{T}$ - treatment group; DIM - days in milk; T $\times$ DIM - interaction between treatment group and days in milk 


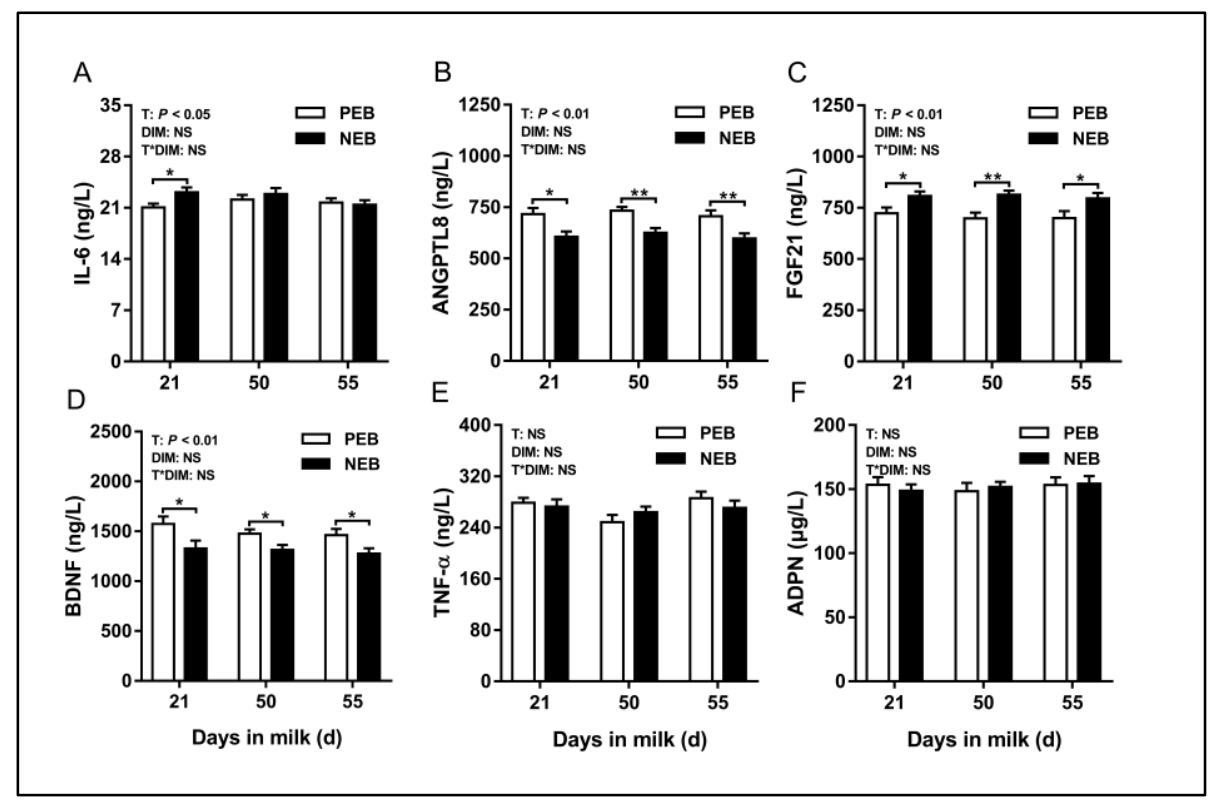

Fig. 4. Least squares mean ( \pm SEM) concentrations of plasma IL-6, ANGPTL8, FGF21, BDNF, TNF- $\alpha$, and $\mathrm{ADPN}$ at 21,50 , and $55 \mathrm{~d}$ after calving for positive energy balance (PEB) $(\mathrm{n}=15)$ and negative energy balance $(\mathrm{NEB})(\mathrm{n}=15)$ dairy cows

$\mathrm{T}$ - treatment group; DIM - days in milk; T $\times$ DIM - interaction between treatment group and days in milk

\section{Discussion}

The energy balance of the body in the postpartum period in dairy cows is crucial to the growth and development of follicles. In the current study, our results showed that there were a significant increase in $\triangle \mathrm{BCS}$ and a lower MY in the NEB group compared with the PEB group. These findings indicated that cows with NEB might experience more fat mobilisation during early lactation. In addition, we also observed that NEB raised the plasma concentrations of BHBA, NEFA, TG and UN, while it lowered those of GLU and TC. Consistent with the findings of a previous experimentally induced NEB study, these results likewise indicated the occurrence of NEB in the present study, more concurrence between this investigation and previous studies also being the latter's confirmation of the relationship between energy metabolites and follicular development (12, 17, 24, 29). Higher plasma BHBA and NEFA concentrations and lower GLU concentrations were not conducive to ovulation in dairy cows (14). On d 7 of the first oestrus cycle, cows with low plasma cholesterol tended to have smaller follicular populations during the ovulatory period (16). In addition, the results of some in vitro studies also indicate that high levels of BHBA and NEFA can inhibit the survival and growth of sheep preantral follicles and their oocytes cultured in vitro (22). Metabolites such as GLU, TC and BHBA affect the maturation ability of oocytes in dairy cows (8). In this study, compared with the follicular growth rate in PEB cows, the rate in NEB cows 50-55 d postpartum is significantly reduced. Therefore, the abnormal energy metabolism caused by NEB in the early lactation of dairy cows hinders the normal growth and development of follicles at this time.
Mineral deficiencies can be either primary or secondary and their effects on reproduction either direct or indirect. In general, primary mineral deficiencies result from a lack of a particular mineral in the diet. In comparison, secondary mineral deficiencies are the result of some other compound in the diet, often another mineral, interfering with the absorption of the deficient element (e.g., sulphur, molybdenum, iron and calcium in the diet reducing the absorption of copper) (26). The clinically defined thresholds for $\mathrm{Ca}, \mathrm{P}$, and $\mathrm{Mg}$ deficiency are plasma concentrations $<2.00 \mathrm{mmol} / \mathrm{L}$ (34), $<1.40 \mathrm{mmol} / \mathrm{L}(33)$, and $<0.80 \mathrm{mmol} / \mathrm{L}(23)$, respectively. To date, however, only a limited number of studies have shown that the mean size of the first ovulated follicles was significantly smaller in cows showing episodes of subclinical hypocalcaemia and that the mean number of ovulatory-sized follicles was lower in these cows (13). Although there is a paucity of reports on the direct influence of hypophosphataemia and hypomagnesaemia on the growth and development of follicles, their occurrence will greatly increase the risk of hypocalcaemia in dairy cows (26). Nevertheless, in this study, the growth rate of follicles in NEB cows 50-55 d postpartum was significantly reduced from the rate in PEB cows, but the plasma $\mathrm{Ca}, \mathrm{P}$, and $\mathrm{Mg}$ levels of the two groups at 21,50 , and $55 \mathrm{~d}$ postpartum were not significantly different and were within the normal ranges. Therefore, it is not through mineral depletion that NEB in early lactation affects the growth and development of follicles at 50-55 d postpartum.

The metabolic homeostasis of dairy cows in early lactation is closely related to endocrines and nutrition, and nutrition can regulate the level of metabolic hormones (such as GH, INS, IGF, and LEP). When dairy cows are in the NEB state after calving, plasma GLU 
levels decrease, resulting in increased glucagon secretion and decreased INS levels (15). Low plasma INS levels reduce glucose uptake by insulin-responsive peripheral tissues (adipose and muscle) and facilitate greater uptake of glucose by the mammary gland, a tissue that is not insulin-responsive. The inability of $\mathrm{GH}$ to stimulate hepatic IGF-1 production during periods of NEB is termed "GH resistance". This is mainly because low levels of plasma INS inhibit the expression of hepatic growth hormone receptor-1A, resulting in uncoupling of the GH/IGF-1 axis, which leads to a decrease in the plasma concentration of IGF-1 (1). Changes in plasma GH over the same period are opposite in trend to those of IGF-1 and INS. Plasma IGFBP-3 is the main binding protein in the regulation system of IGF-1, is most closely related to IGF, and can freely regulate the concentration of IGF. In severe NEB states, the expression of IGF-1 and IGFBP-3 genes in the liver of dairy cows was significantly reduced (7). The plasma LEP level of dairy cows is positively correlated with the energy level of the body. Therefore, the plasma LEP level decreases in the NEB state.

However, metabolic hormones had a direct effect on follicular growth and maturation. Previous studies showed that INS and IGF-1 in plasma could affect the development of oocytes and promote the proliferation of ovarian granulosa cells and the secretion of steroids. In addition, IGF-1 can also regulate the secretion of $\mathrm{P} 4$ and LH (32). In the NEB state, the plasma IGF-1 level of dairy cows will continue to decrease, which will delay the growth of follicles, reduce E2 synthesis and delay ovulation (35). Insulin is also related to the synthesis of steroids, which can regulate the reactions related to the synthesis and secretion of gonadal hormones in granular cells and promote the production of E2 in granular cells at normal physiological concentrations. The plasma glucose and INS content of NEB dairy cows decreased, and INS stimulated the development of follicular cells of dairy cows in vitro and in vivo. Leptin is closely related to reproduction and is a necessary factor for maintaining a normal ovarian cycle. The hypothalamus, pituitary gland, gonads, and uterus all have receptors for this hormone, and it can stimulate the secretion of $\mathrm{GnRH}$, $\mathrm{LH}, \mathrm{FSH}$ and $\mathrm{E} 2$ and affect reproduction by affecting the hypothalamic-pituitary-gonadal axis. In the NEB state, the plasma LEP content of dairy cows decreases, which affects the postpartum oestrus of dairy cows. In summary, NEB causes a decrease in the concentration of INS and IGF-1, and the consequent increase in the concentration of $\mathrm{GH}$ reduces the concentration of LEP, thereby inhibiting the secretion of E2 and P4 and hindering the growth and development of follicles. Therefore, NEB in early lactation affects the growth and development of follicles at $50-55 \mathrm{~d}$ postpartum by causing abnormal changes in hormones.

At present, the role of cytokines in the process by which NEB affects follicular development in dairy cows is still unclear. BDNF in the hypothalamus plays an important role in regulation of energy balance.
A considerable body of evidence links diminished BDNF signalling to energy balance dysregulation in humans and rodents $(18,25)$. Energy insufficiency is the cause of chronically elevated FGF21 in early lactation (28). Hepatic ANGPTL8 production was downregulated in the postpartum period when the cows experienced a negative energy balance. This downregulation was associated with increased concentrations of NEFA and decreased concentrations of INS in lactating cows, and it facilitated lipid mobilisation from adipose tissue to the mammary glands (21). In this study, $21 \mathrm{~d}$ into the postpartum period, plasma IL-6 and FGF21 levels in NEB cows were significantly higher than those in PEB cows. However, plasma BDNF and ANGPTL8 levels were decreased in the NEB cows. Except for IL-6, these differences in FGF21, BDNF and ANGPTL8 all persisted to $\mathrm{d} 50-55$ of the postpartum period. It can be seen that the significant increase in plasma IL-6 levels four weeks earlier may be related to the occurrence of clinical ketosis in NEB cows. In addition, high levels of BDNF promoted oocyte maturation, and low levels of FGF21 abrogated the preserving effect of low protein intake on the primordial follicle pool, thereby activating primordial follicles $(31,37)$. However, there is no report on the effect of ANGPTL8 on follicular development in dairy cows. Therefore, the abnormal changes in cytokines caused by NEB in the early stage of lactation in dairy cows can also interfere with the normal growth and development of follicles in the eighth week postpartum. Further research is warranted on the roles of cytokines in follicular growth because deeper knowledge of their mechanism of action will clarify some important reproductive implications in bovines.

In conclusion, negative energy status was associated with greater $\triangle \mathrm{BCS}$, higher plasma concentrations of BHBA and NEFA, and a lower one of GLU during the postpartum period on $\mathrm{d} 21,50$, and 55 . Plasma hormones were in smaller presence during the study period in NEB cows, whereas plasma minerals were not affected by energy status. In addition, NEB cows had upward and downward changes in plasma cytokines. NEB cows had a weaker follicular growth rate eight weeks postpartum than PEB cows, which was associated with measurable changes in energy metabolites, hormones and cytokines caused by earlier postpartum NEB. These observations indicate that follicular growth rate is associated with measurable changes in energy metabolites, hormones and cytokines caused by early postpartum NEB.

*Yuxi Song and Zhijie Wang made equal contributions to this work.

Conflict of Interests Statement: The authors declare that there is no conflict of interests regarding the publication of this article.

Financial Disclosure Statement: The study was supported by the National Science Foundation 
Committee of China (31772804) and the Heilongjiang Bayi Agriculture University graduate student innovation fund project (YJSCX2019-Y38).

Animal Rights Statement: The study protocol was approved by the Ethics Committee on the Use and Care of Animals of Heilongjiang Bayi Agricultural University (Daqing, China). All experimental animals were treated according to the International Guiding Principles for Biomedical Research Involving Animals (Pan American Health Organisation, 2010).

Acknowledgments: The authors would like to thank International Science Editing.

\section{References}

1. Butler S.T., Marr A.L., Pelton S.H., Radcliff R.P., Lucy M.C., Butler W.R.: Insulin restores GH responsiveness during lactationinduced negative energy balance in dairy cattle: effects on expression of IGF-I and GH receptor 1A. J Endocrinol 2003, 176, 205-217, doi: 10.1677/joe.0.1760205.

2. Caixeta L.S., Ospina P.A., Capel M.B., Nydam D.V.: The association of subclinical hypocalcemia, negative energy balance and disease with bodyweight change during the first 30 days postpartum in dairy cows milked with automatic milking systems. Vet J 2015, 204, 150-156, doi: 10.1016/j.tvj1.2015.01.021.

3. Drackley J.K.: American Dairy Science Association foundation scholar award. Biology of dairy cows during the transition period: the final frontier. J Dairy Sci 1999, 82, 2259-2273, doi: 10.3168/jds.S0022-0302(99)75474-3.

4. Edmonson A.J., Lean I.J., Weaver L.D., Farver T., Webster G.: A body condition scoring chart for Holstein dairy cows. J Dairy Sci 1989, 72, 68-78, doi: 10.3168/jds.S0022-0302(89)79081-0.

5. El-Tarabany M.S.: Impact of days in milk at the initiation of ovulation synchronization protocols on the efficiency of first AI in multiparous Holstein cows. Anim Reprod Sci 2017, 182, 104-110, doi: 10.1016/j.anireprosci.2017.05.005.

6. Enjalbert F., Nicot M.C., Bayourthe C., Moncoulon R.: Ketone bodies in milk and blood of dairy cows: relationship between concentrations and utilization for detection of subclinical ketosis. J Dairy Sci 2001，84，583-589, doi: 10.3168/jds.S00220302(01)74511-0.

7. Fenwick M.A., Fitzpatrick R., Kenny D.A., Diskin M.G., Patton J., Murphy J.J., Wathes D.C.: Interrelationships between negative energy balance (NEB) and IGF regulation in liver of lactating dairy cows. Domest Anim Endocrinol 2008, 34, 31-44, doi: 10.1016/j.domaniend.2006.10.002.

8. Ferreira F.A., Gomez R.G., Joaquim D.C., Watanabe Y.F., de Castro e Paula L.A., Binelli M., Rodrigues P.H.: Short-term urea feeding decreases in vitro hatching of bovine blastocysts. Theriogenology 2011, 76, 312-319, doi: 10.1016/ j.theriogenology.2011.02.008.

9. Forde N., Beltman M.E., Lonergan P., Diskin M.G., Roche J.F., Crowe M.A.: Oestrous cycles in Bos taurus cattle. Anim Reprod Sci 2011, 124, 163-169, doi: 10.1016/j.anireprosci.2010.08.025.

10. Galic S., Oakhill J.S., Steinberg G.R.: Adipose tissue as an endocrine organ. Mol Cell Endocrinol 2010, 316, 129-139, doi: 10.1016/j.mce.2009.08.018

11. Ho C.-F., Chan K.-W., Yeh H.-I., Kuo J., Liu H.-J., Wang C.-Y.: Ketone bodies upregulate endothelial connexin $43(\mathrm{Cx} 43)$ gap junctions. Vet J 2013, 198, 696-701, doi: 10.1016/j.tvj1.2013.09.069.

12. Ihsanullah., Qureshi M.S., Suhail S.M., Akhtar S., Khan R.U.: Postpartum endocrine activities, metabolic attributes and milk yield are influenced by thermal stress in crossbred dairy cows. Int
J Biometeorol 2017, 61, 1561-1569, doi: 10.1007/s00484-0171335 -z.

13. Kamgarpour R., Daniel R.C., Fenwick D.C., McGuigan K., Murphy G.: Post partum subclinical hypocalcaemia and effects on ovarian function and uterine involution in a dairy herd. Vet J 1999, 158, 59-67, doi: 10.1053/tvjl.1999.0348.

14. Kawashima C., Matsui M., Shimizu T., Kida K., Miyamoto A.: Nutritional factors that regulate ovulation of the dominant follicle during the first follicular wave postpartum in high-producing dairy cows. J Reprod Dev 2012, 58, 10-16, doi: 10.1262/jrd.11139 n.

15. Kawashima C., Sakaguchi M., Suzuki T., Sasamoto Y., Takahashi Y., Matsui M., Miyamoto A.: Metabolic profiles in ovulatory and anovulatory primiparous dairy cows during the first follicular wave postpartum. J Reprod Dev 2007, 53, 113-120, doi: $10.1262 /$ jrd. 18105 .

16. Lammoglia M.A., Willard S.T., Hallford D.M., Randel R.D.: Effects of dietary fat on follicular development and circulating concentrations of lipids, insulin, progesterone, estradiol-17 beta, 13,14-dihydro-15-keto-prostaglandin $\mathrm{F}(2$ alpha), and growth hormone in estrous cyclic Brahman cows. J Anim Sci 1997, 75, 1591-1600, doi: 10.2527/1997.7561591x.

17. Leroy J.L., Van Soom A., Opsomer G., Bols P.E.: The consequences of metabolic changes in high-yielding dairy cows on oocyte and embryo quality. Animal 2008, 2, 1120-1127, doi: $10.1017 / \mathrm{S} 1751731108002383$.

18. Liu X., Zhu Z., Kalyani M., Janik J.M., Shi H.-F.: Effects of energy status and diet on Bdnf expression in the ventromedial hypothalamus of male and female rats. Physiol Behav 2014, 130, 99-107, doi: 10.1016/j.physbeh.2014.03.028.

19. Macmillan K., Gobikrushanth M., López Helguera I., Behrouzi A., Colazo M.G.: Relationships between early postpartum nutritional and metabolic profiles and subsequent reproductive performance of lactating dairy cows. Theriogenology 2020, 151, 52-57, doi: 10.1016/j.theriogenology.2020.03.034.

20. Montiel F., Ahuja C.: Body condition and suckling as factors influencing the duration of postpartum anestrus in cattle: a review. Anim Reprod Sci 2005, 85, 1-26, doi: 10.1016/j.anireprosci. 2003.11.001

21. Nakano M., Suzuki Y., Haga S., Yamauchi E., Kim D., Nishihara K., Nakajima K., Gotoh T., Park S., Baik M., Katoh K., Roh S.: Downregulated angiopoietin-like protein 8 production at calving related to changes in lipid metabolism in dairy cows. J Anim Sci 2018, 96, 2646-2658, doi: 10.1093/jas/sky162.

22. Nandi S., Tripathi S.K., Gupta P.S.P., Mondal S.: Effect of metabolic stressors on survival and growth of in vitro cultured ovine preantral follicles and enclosed oocytes. Theriogenology 2017, 104, 80-86, doi: 10.1016/j.theriogenology.2017.07.024.

23. Neves R.C., Leno B.M., Stokol T., Overton T.R., McArt J.A.A.: Risk factors associated with postpartum subclinical hypocalcemia in dairy cows. J Dairy Sci 2017, 100, 3796-3804, doi: 10.3168/jds.2016-11970.

24. Newman A., Mann S., Nydam D.V., Overton T.R., Behling-Kelly E.: Impact of dietary plane of energy during the dry period on lipoprotein parameters in the transition period in dairy cattle. J Anim Physiol Anim Nutr (Berl) 2016, 100, 118-126, doi: $10.1111 /$ jpn. 12343 .

25. Rios M.: BDNF and the central control of feeding: accidental bystander or essential player. Trends Neurosci 2013, 36, 83-90, doi: 10.1016/j.tins.2012.12.009.

26. Roche J.R., Burke C.R., Crookenden M.A., Heiser A., Loor J.L., Meier S., Mitchell M.D., Phyn C.V.C., Turner S.-A.: Fertility and the transition dairy cow. Reprod Fertil Dev 2017, 30, 85-100, doi: 10.1071/RD17412.

27. Rutherford A.J., Oikonomou G., Smith R.F.: The effect of subclinical ketosis on activity at estrus and reproductive performance in dairy cattle. J Dairy Sci 2016, 99, 4808-4815, doi: $10.3168 /$ jds. 2015-10154.

28. Schoenberg K.M., Giesy S.L., Harvatine K.J., Waldron M.R., Cheng C., Kharitonenkov A., Boisclair Y.R.: Plasma FGF21 is elevated by the intense lipid mobilization of lactation. 
Endocrinology 2011，152，4652-4661, doi: 10.1210/en.20111425.

29. Shingu H., Hodate K., Kushibiki S., Touno E., Oshibe A., Ueda Y., Shinoda M., Ohashi S.: Effects of growth hormone-releasing hormone treatment on milk production and plasma hormones and metabolites in lactating Japanese Black cows under negative energy balance. J Anim Sci 2009, 87, 1247-1253, doi: 10.2527/jas.2008-1220.

30. Stangaferro M.L., Wijma R.W., Giordano J.O.: Profitability of dairy cows submitted to the first service with the PresynchOvsynch or Double-Ovsynch protocol and different duration of the voluntary waiting period. J Dairy Sci 2019, 102, 4546-4562, doi: $10.3168 /$ jds.2018-15567.

31. Streiter S., Fisch B., Sabbah B., Ao A., Abir R.: The importance of neuronal growth factors in the ovary. Mol Hum Reprod 2016, 22, 3-17, doi: 10.1093/molehr/gav057.

32. Thatcher W.W., Bilby T.R., Bartolome J.A., Silvestre F., Staples C.R., Santos J.E.: Strategies for improving fertility in the modern dairy cow. Theriogenology 2006, 65, 30-44, doi: 10.1016/ j.theriogenology.2005.10.004.

33. Tsiamadis V., Banos G., Panousis N., Kritsepi-Konstantinou M., Arsenos G., Valergakis G.E.: Genetic parameters of subclinical macromineral disorders and major clinical diseases in postparturient Holstein cows. J Dairy Sci 2016, 99, 8901-8914, doi: 10.3168/jds.2015-10789.

34. Venjakob P.L., Pieper L., Heuwieser W., Borchardt S.: Association of postpartum hypocalcemia with early-lactation milk yield, reproductive performance, and culling in dairy cows. J Dairy Sci 2018, 101, 9396-9405, doi: 10.3168/jds.2017-1420.

35. Wathes D.C., Fenwick M.A., Cheng Z., Bourne N., Llewellyn S., Morris D.G., Kenny D.A., Murphy J.J., Fitzpatrick R.: Influence of negative energy balance on cyclicity and fertility in the high producing dairy cow. Theriogenology 2007, 68, 232-241, doi: 10.1016/j.theriogenology.2007.04.006.

36. Zhao C., Shu S., Bai Y.-L., Wang D., Xia C., Xu C.: Plasma protein comparison between dairy cows with inactive ovaries and estrus. Sci Rep 2019, 9, 13709, doi: 10.1038/s41598-019-49785-8.

37. Zhuo Y., Hua L., Feng B., Jiang X., Li J., Jiang D., Huang X., Zhu Y., Li Z., Yan L., Jin C., Che L., Fang Z., Lin Y., Xu S., Li J., Wu D.: Fibroblast growth factor 21 coordinates adiponectin to mediate the beneficial effects of low-protein diet on primordial follicle reserve. EBioMedicine 2019, 41, 623-635, doi: 10.1016/ j.ebiom.2019.02.020. 